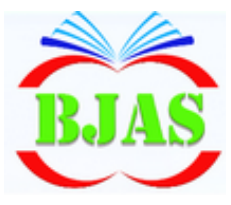

ISSN 1814 - 5868
Available online at http://bajas.edu.iq

https://doi.org/10.37077/25200860.2019.207

College of Agriculture, University of Basrah

Basrah J. Agric. Sci., 32(2) 169-175, 2019

\section{Basrah Journal of Agricultural Sciences}

E-ISSN: 2520-0860

\title{
Taxonomic Study of some Species of Flower Flies (Diptera: Syrphidae) at Basrah Province
}

\author{
Abdul Rahman A. Atta*, Alaa S. Jabbar \& Ayad A. Abdulkader \\ Department of Plant Production, College of Agriculture, University of Basrah, Iraq \\ *Corresponding author E-mail: aalrhman862@gmail.com \\ Received 19 September 2019; Accepted 18 November 2019; Available online 31 December 2019
}

\begin{abstract}
The current study were carried out to identify of five species belong to the flower fly family Syrphidae, depending on male genitilia. They included Episyrphus balteatus De Geer, 1776; Eupeodes corollae Fabricius, 1794; Sphaerophoria scripta Linnaeus, 1758; Eristalinus aeneus Scopoli, 1763; Eristalis tenax Linnaeus, 1758, from some Basrah province.
\end{abstract}

Keywords: Classification, Insect, Diptera, Syrphidae, Iraq.

\section{Introduction}

The family Syrphidae belongs to the order Diptera, called Hoverflies or flower Flies (Hassan et al., 2019). It spreads in most regions of the world and has about 180 genera and 6000 species (Thompson, 2013; Ghorpadé, 2014). They are characterized by bright colors (Ross, 1948). They feed on pollen and nectar, so they are important as pollinators (Rotheray \& Gilbert, 1999). Many species of Syrphidae mimics some insects of the Vespidae \& Apoidae (Hymenoptera), so they can escape from the predators (Golding et al., 2005). Hennig (2011) reported that Eristalis tenax and Episyrphus balteatus are dominant of some plant species such as Chrysanthemum sp. and Anchusa sp. on the other hand, the rat-tailed larvae of Eristalis sometime internally infest man when they drink contaminated water containing the eggs or young larvae (Coe, 1953). Entwistle \& Dixon (1989) found that fly larvae of Episyrphus balteatus are important predators in regulating the numerical density of Aphids.
Some studies have indicated that larvae of some species of this family are predators for other insects, such as Aphids and Scale insects. Bigot (1892) published a catalogue of Indian Syrphid flies. Telford (1970) identified 27 species from northern Mexico that belong to the genus Eristalis Latreille. Thompson (2003) described new genus and species of flower flies from the Australian, Biotic region Eristalis resolutus Walker, Eristalis rhina Thompson. Saribiyik (2003) described 52 species belonging to two subfamilies (Syrphinae and Milesiinae) in Turkey. Steyskal \& Bialy (1967) listed 47 species in the Egyptian fauna. Abdul-Rassoul (1976) recorded two species Tubifera aenea (Sco.) and T. tenax (L.) in Iraq. Mohamed \& Abdullah (1989) recorded Syrphus corolla on pomegranate aphids in Mosel, Iraq. The current study aims to identify species of flower flies depending on male genitalia at different regions of Basrah province. 
Atta et al. / Basrah J. Agric. Sci., 32 (2): 179-185, 2019

\section{Materials \& Methods}

\section{Collection of insects}

Samples were collected by using insect collecting net to capture the flies on the flowers or that hovering in the air near the flowers, at different regions (Qurna, Madinah, Aldiyr, Haritha , Karmat Ali, Shatt Al Arab, and Abu Al-Khaseeb) of Basrah province, Iraq from $1^{\text {st }}$ October 2017 to 15 September 2018.

\section{Preparation of microscopic slides}

For the purpose of studying some characteristics of flower flies, models of male adult insects selected and cleaned with a fine brush to remove the suspended parts on the body; some parts of the insect isolated by separating the organ to be studied under the dissection microscope, then placed in $20 \%$ $\mathrm{KOH}$ solution for 24 hours to obtain the desired transparency, and then washed by distilled water. After that the samples were passed through ascending concentrations of alcohol 50-70-90\%, respectively for two minutes each time. The dissected parts were mounted on microscopic slides and added xylol and canada balsam with arranging the parts correctly and then covered with the cover slide, All slides were placed on the hot plate to remove the air bubbles in the medium. The illustrations were drawn by the Lucida camera and the measurements were taken by using the ocular micrometer in the microscope after compared with the phase micrometer (Wallis, 2005). The flower flies were identified different taxonomical keys were used (Coe, 1953; Curran, 1965; Daniel \& Drew, 1976; Thompson, 1997).

\section{Results}

\section{Episyrphus balteatus De Geer, 1776}

Description of Male terminalia: (Fig. 1)

Ninth tergites nearly $\mathrm{C}$ formed, brownness, with short black bristles. Anal cerci cannular, brownness lightly recurved internally its surface coated with short dark brown bristles. Stylus oval shaped and yellowish, its outer surface covered with short light brown hair. Adages light brown to yellow colour its length $(0.82-0.86) \mathrm{mm}$, its base is dark brown and its front face looks like a knot.

\section{Eupeodes corollae Fabricius, 1794}

Male terminalia: (Fig. 2)

Ninth tergite dome formed, brown, with very little dense of short brown hairs. Anal cerci cannula formed, brown, with slightly acetabular internal margin, its surface coated with moderate dense short brown hairs. Stylus falcate out ward, dark brown, its internal margin with very little dense short brown spines and therefore the remainder of the surface coated with moderately dense short brown hairs. Adages brown, (1.28-1.30) $\mathrm{mm}$ length, its base elongated oval formed, brown and its front hook like formed, brown.

\section{Sphaerophoria scripta Linnaeus, 1758}

Male terminalia: (Fig. 3)

Ninth tergite dome formed, brown, with short, brownness hairs. Anal cerci square formed, brownness, with a hook like Extension at internal top margin, its internal margin coated with extremely dense, of short, black spines and the margin of this extension coated with short, brown hairs. Stylus broad, nearly rectangular formed, 


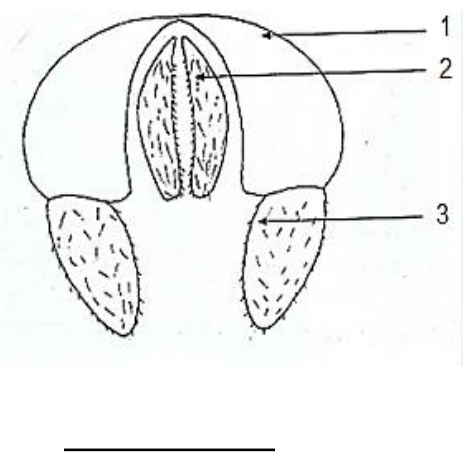

A

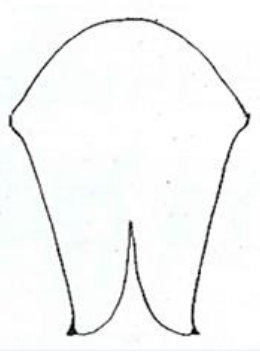

B

Fig. (1): Male terminalia of Episyrphus balteatus.

\section{A- The ninth abdominal ring of the male, B- Adages. Abbreviations: 1- Tergum nine, 2-Anal cerci, 3- Stylus. \\ Scale bar: $A=0.5 \mathrm{~mm}$,}

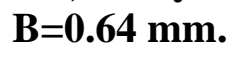

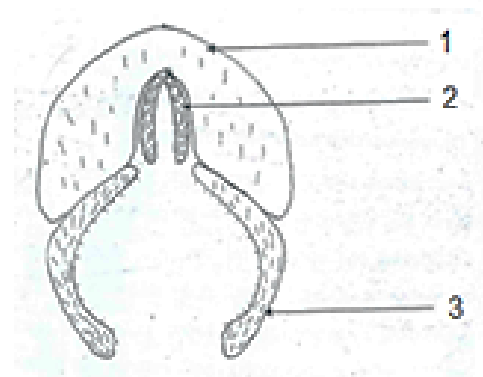

A

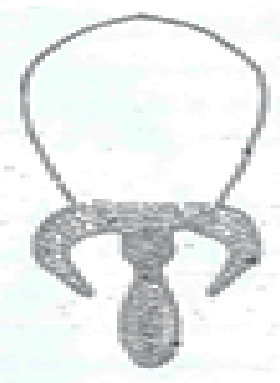

B

Fig. (2): Male terminalia of Eupeodes corolla.

\section{A- The ninth abdominal ring of the male, B- Adages. Abbreviations: 1- Tergum nine, 2-Anal} cerci, 3- Stylus. Scale bar: $A=0.71, B=0.5 \mathrm{~mm}$.

brown, its top margin coated with extremely dense long, of sunshine brown hairs, and also the remainder of the surface with short, brownness hairs. Adages piker formed, brown, (1.17-2.00) $\mathrm{mm}$ length; its base elongated rectangular formed, with slightly cupulate at basal lateral margin and spherical shaped.

\section{Eristalinus aeneus Scopoli, 1763}

Male terminalia: (Fig. 4)

Ninth tergite brown, lined with moderately dense, short brownness hairs, its anterior margin bowl-shaped, whereas its posterior margin infolded as inverted U letter formed. Anal cerci nearly cannular formed, brown, its posterior margin rounded, its whole surface lined with long brownness hairs. Stylus light brown-yellow, its top outer margin slightly bowl-shaped, and its internal basal with dense thick short black bristles. Adages brownyellow, (1.80- 1.85) $\mathrm{mm}$ in length, its base rounded, moderately sclerotized and its front terribly short, rounded sort of a tiny projection. 


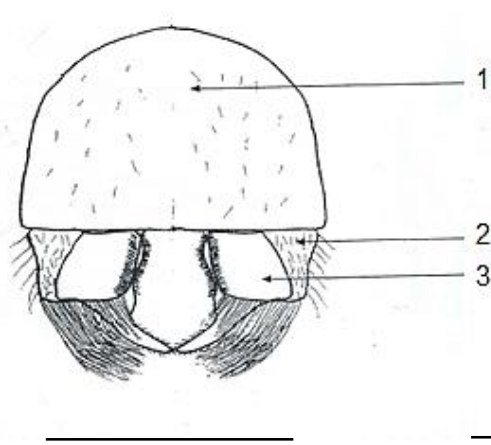

A

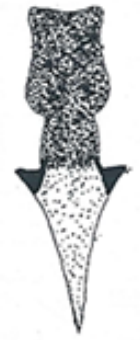

B

Fig. (3): Male terminalia of Sphaerophoria scripta.

A) The ninth abdominal ring of the male (B) Adages. Abbreviations: 1- Tergum nine, 2-Anal cerci, 3- Stylus. Scale bar: $A=1 \mathrm{~mm}, B=1.18 \mathrm{~mm}$.

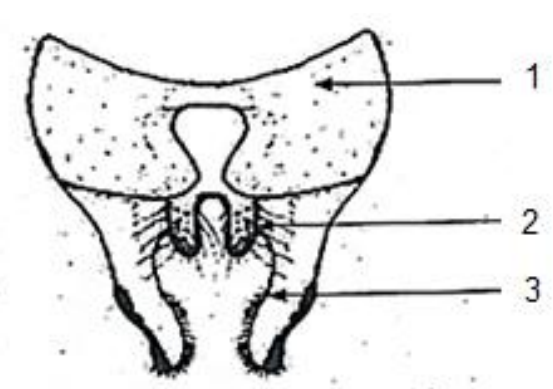

A

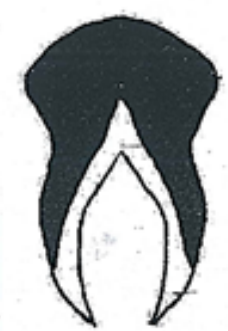

B

Fig. (4): Male terminalia of Eristalinus aeneus.

(A) The ninth abdominal ring of the male (B) Adages. Abbreviations: 1- Tergum nine, 2-Anal cerci, 3- Stylus. Scale bar: A \& B= 1 mm.

Earistalis tenax Linnaeus, 1758

Male terminalia: (fig. 5)

Ninth tergite dark, its anterior margin intrus, with extremely concavity posterior margin. Anal cerci oval formed, brown-yellow, with an outsized area between its terminal ends, its dorsal surface coated with densel, long light brown-yellow hairs. Stylus oval formed, and tapering top surface with high dense of short dark brown-black bristles, the rest surface with moderate densely long brown hairs. Adages brown light-brown, (1.55-1.60) $\mathrm{mm}$ length; its base curved, slightly sclerotized and its front nearly cannula formed, slightly sclerotize. 


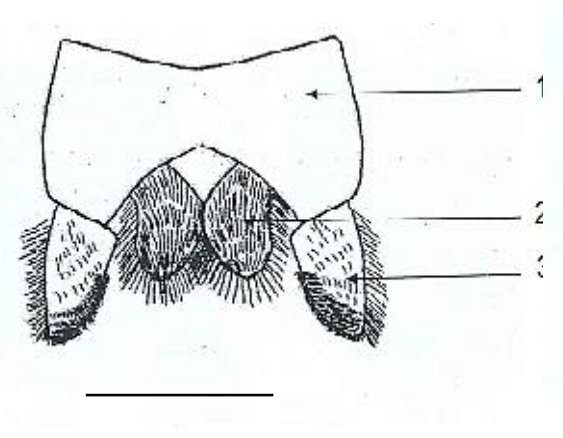

A

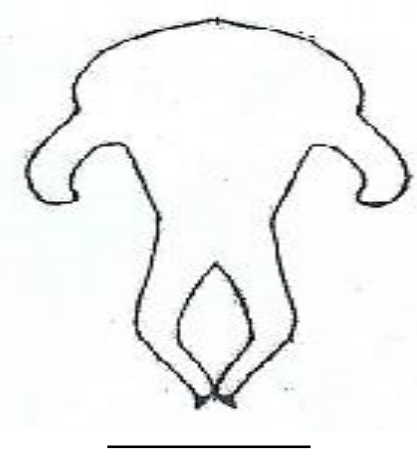

B

Fig. (5): Male terminalia of Earistalis tenax.

\section{A-The ninth abdominal ring of the male. B- Adages. Abbreviations: 1- Tergum nine, 2-Anal cerci, 3- Stylus. Scale bar: A \& B=1 mm.}

\section{Discussion}

The results of this research indicate that there is a diverse fauna of Syrphidae in Basrah province, and it was expected that some other species still were not discovered. To record new species, more studies should be conducted on this important insect group in Basrah province. This study recorded and identified five species belong to four genera Episyrphus balteatus, Sphaerophoria scripta, Eupeodes corollae, Eristalis aeneus and Eristalis tenax, depending on the shape and size male genitalia. These species were widely distributed in most of the sampled regions. The larva of many species of hoverflies, particularly subfamily Syrphinae are important predators of aphids and other agricultural pests that can play an important role in the biological control (Müller \& Godfrey 1999). Therefore the faunistic surveys on these beneficial insects must be continued in order to determine the species diversity of syrphids in the mentioned province and also other areas of Iraq. Swailem et al. (1974) recorded Eristalis tenax L. in Mosel, Iraq. Maaroof \& Amin (1989) recorded Metasyrphus corollae on peach aphids in Mosel. Hussein (2013) recorded two species of Syrphid fly Metasyrphus taeniops and Episyrphus balteatus in Al-Qadisiyah. Abdulrazaak (2014) recorded and identified five species Episyrphus balteatus, Metasyrphus corollae, Syrphus ribessi, Sphaerophoria scripta, Eristalis arbustorum in Thi-qar. Al-Saffar \& Augul (2015) recorded Sphaerophoria scripta in two provinces (Baghdad and Karbala) of Iraq. Kridi (2016) recorded four species, Sphaerophoria sp., Eupeodes sp., Eristalis sp. \& Syrphus sp. in Misan. Mouhammed (2017) recorded one species of Syrphid fly Scaeva pyrastri in Basrah. Telford(1970) identified 27 species from north Mexico that belong to the genus Eristalis based on color pattern, wing veinations and male genitalia. Nayar (1977) described nine species of Eristalis in Libya and India depending on the abdominal pale marking. Coe (1953) described species Sphaerophoria scripta based on legs which was completely yellow, tergites (2-4 with variable yellow markings), and wing (length 
5.75-7 mm). Wright \& Skevington (2013) identified subgenus Episyrphus just based on Eye. Subhan \& Shah (2016) explained that Sphaerophoria could be identified by the mesonotum (lateral yellow margins), facial black median vitta which is very weak.

\section{Conclusions:}

Five species of flower flies, Episyrphus balteatus, Sphaerophoria scripta, Eupeodes corollae, Eristalis aeneus and Eristalis tenax, were identified depending on the shape and size male genitalia on Basrah province. They were more abundant in April and October.

\section{Acknowledgement}

I would like to thank Dr Muhammad S. Abdul-Rassoul from Natural History Museum, Baghdad, Iraq for his help with diagnosis of the insects.

Conflict of interest: The authors declare that they have no conflict of interest.

\section{References}

Abdul-Rassoul, M.S. (1976). Checklist of Iraq natural history museum Insects Collection. Nat. Hist. Res. Cen., Iraq, Pub.1, No. 30: 41pp.

Abdulrazaak, K.J. (2014). A Taxonomic study of some species of syrphid fly in Thi-Qar province. Thi-Qar Univ. J. Agric. Res., 3(2): 219-233.

Al-Saffar, H.H., \& Augul, R.S. (2015). Survey of Brachycera; Diptera from several regions of Iraq. Bulletin of the Iraq Natural History Museum, 13(3): 59-69.

Bigot, J.M.F. (1892). Catalogue of Diptera of Oriental region. J. Asiatic Soc. Bengal., 2: 228-236. Coe, R.L. (1953). Handbook for the Identification of British Insects. Roy. Entom. Soc., London, 10(1): 1-98.
Curran, C.H. (1965). The Families and Genera of North America Diptera. $2^{\text {nd }}$ ed. Henry Tripp. New York: 515pp.

Daniel, A.S. \& Drew, W.A. (1976). Syrphidae of the Oklahoma (Diptera). Proc. Okla. Acad. Sci., 56: 1-75.

Entwistle, J.C. \& Dixon, A.F.G. (1989). The effect of augmenting grain aphid (Sitobion avenue) numbers in a field of winter wheat in spring on the aphid's abundance in summer and its relevance to the forecasting of outbreaks. Annals Appl. Biol., 114: 397408.

Ghorpadé, K. (2014). An updated checklist of the hover-flies (Diptera-Syrphidae) recorded in the Indian subcontinent. Colemania, 44: 1-30.

Golding, Y.; Edmunds, M. \& Ennos, A.R. (2005). Flight behaviour during foraging of the social wasp Vespula vulgaris (Hymenoptera: Vespidae) and four mimetic hoverflies (Diptera: Syrphidae) Sericomyia silentis, Myathropa florea, Helophilus sp. and Syrphus sp. J. Exp. Biol., 208: 4523-4527.

Hassan, M.A.; Bodlah I.; Bodlah, M.A. \& Hussain, R. (2019). New records of the genus Ceriana Rafinesque, 1815 (Diptera: Syrphidae) from Pakistan. Munis Entomol. Zool., 14 (1): 185-187.

Hennig, E.I. (2011). Plant-pollinator interactions within the urban environment. Perspect. Plant Ecol., 13(2): 137-150.

Hussein, H.M. (2013). Daily activity of some local pollinators for alfalfa crop Trifolium alexenderianum in Al-Qadisiyah. J. Univ. Babylon. 3(20): 901-909.

Kridi, A.A. (2016). Survey and identification some pollinators and pollen resources in 
Missan. Thesis. Dept. Plant Protection, Coll. Agric., Univ. Basrah: 91pp.

Maaroof, A.A. \& Amin, A.H. (1989). The presence and seasonal spread of an insect Pemphigus lichtensteini Talg. (Aphididae: Homoptera) in Mosel. Mesopot. J. Agric., 18(1): 195-203.

Mohamed, M.A. \& Abdullah, S.E. (1989). Environmental and biological study on Aphids pomegranate insect in the Mosul area. Mesopotamia J. Agric., 21(3): 279310.

Mouhammed, Z.J. (2017). Diagnostic study of some species of aphid on wheat crop and bilogical control in provinces of Maysan and Basrah. M. Sc. Thesis. Dept. Plant Protection, Coll. Agric., Univ. Basrah: 82pp.

Müller, C.B. \& Godfrey, H.C.J. (1999). Predators and mutualists influence the exclusion of aphid species from natural communities. Oecologia, 119: 120-125.

Nayar, J.L. (1977). Abdominal Teratology in Eristalis tenax (L.) from Libya and Indie. Orienta Insects, 11(4): 639-642.

Ross, H.H. (1948). A Textbook of Entomology. John Wiley \& Sons, Inc., $2^{\text {nd }}$ ed. New York: 487pp.

Rotheray, G.E. \& Gilbert F.S. (1999). Phylogeny of Palaeartic Syrphidae (Diptera) evidence from larval stages. Zoo .J. Linn. Soc. Lond., 127: 1-112.

Saribiyik, S. (2003). Fauna of Syrphidae and Milesiinae (Diptera:Syrphidae) around Tuz lake. Kastamonu Egitim Dergisi., 2: 439450.
Steyskal, C.G. \& Bialy, S. (1967). List of Egyptian Diptera. Tech. Bull. Min. Agric., 3: 12-18.

Subhan, F. \& Shah, M. (2016). Taxonomic study of genus Sphaerophoria Le Peletier et Serville (Diptera: Syrphidae) with three species from Northern dry mountains region of Pakistan. J. Entomol. Zool. Stud., 4(4): 1192-1198.

Swailem, S.M.; Selim, A.A. \& Amin, A.H. (1974). A contribution to the study of the insect fauna of Hammam Al-Alil, Part I. Mesopotamia J. Agric. 9(1-2): 119-141.

Telford, H.S. (1970). Eristalis (Diptera) from America, North of Mexico. Ann. Ent. Soc. Am., 85: 1201-1209.

Thompson, F.C. (1997). Revision of the Eristalis flower flies (Diptera:Syrphidae) of the Americans south of the united states. Proc. Ento. Soc., 99(2): 209-237.

Thompson, F.C. (2003). Austalis, new genus of flower flies (Diptera: Syrphidae) with revisionary notes on related genera. Zootaxa, 246: 1-19.

Thompson, F.C. (2013). Systema Dipterorum, Version 1.5; [Accessed 2015 Jan 10]. Available from: http://www.diptera.org/.

Wallis, C.M. (2005). Aphid (Hemiptera: Aphididae) species composition and potential aphid vectors of Plum PoxVirus in Pennsylvania Peach Orchards, J. Econ. Entomol., 98(5): 1441-1450.

Wright, S.G. \& Skevington, J.H. (2013). Revision of the subgenus Episyrphus (Episyrphus) Matsumura (Diptera: Syrphidae) in Australia. Zootaxa, 3683(1): 51-64. 